\section{Summary}

Two cases of acute uric acid nephropathy complicating acute leukaemia are described.

Some observations have been made which bear on the use of the xanthine oxidase inhibitor allopurinol in the management of acute uric acid nephropathy.

Allopurinol restricts the formation of uric acid in acute leukaemia, but to be effective in reducing the risk of acute uric acid nephropathy it must be given before chemotherapy is begun.

The patients were under the care of Sir Ronald Bodley Scott, K.C.V.O., and we are pleased to acknowledge our indebtedness to him for allowing us to study them, and for his help and encouragement. Some of the work was undertaken in the Medical Professorial Unit (Dunn Laboratories), and we are indebted to Professor E. F. Scowen for his interest. We also wish to thank the Governors of St. Bartholomew's Hospital for their generous research grant, and Burroughs Wellcome and Co. for supplies of allopurinol.

\section{REFERENCES}

Elion, G. B., Callahan, S., Nathan, H., Bieber, S., Rundles, R. W., and Hitchings, G. H. (1963). Biochem. Pharmacol., 12, 85.
— Taylor, T. J., and Hitchings, G. H. (1964). VI International Congress of Biochemistry, New York, Abstracts IV-42.

Engelman, K., Watts, R. W. E., Klinenberg, J. R., Sjoerdsma, A., and Seegmiller, J. E. (1964). Amer. F. Med., 37, 839.

Frei, E., III, Bentzel, C. J., Rieselbach, R., and Block, J. B. (1963). F. chron. Dis., 16, 757.

Goldfiinger, S., Klinenberg, J. R., and Seegmiller, J. E. (1965). F. clin. Invest., 44, 623.

Hall, A. P., Holloway, V. P., and Scott, J. T. (1964). Ann. rheum. Dis., 23, 439.

Klinenberg, J. R., Goldfinger, S., Miller, J., and Seegmiller, J. E. (1963). Arthr. and Rheum., 6, 779.

_ and Seegmiller, J. E. (1965). Ann. intern. Med., 62, 639.

Kritzler, R. A. (1958). Amer. Ұ. Med., 25, 532.

Liddle, L., Seegmiller J. E., and Laster, L. (1959). f. Lab. clin. Med., 54, 903.

Lillie, R. D. (1947). Histopathologic Technic, p. 153. Blakiston, Philadelphia.

McCrea, L. E. (1955). f. Urol., 73, 29.

Metcalfe-Gibson, A., McCallum, F. M., Morrison, R. B. I., and Wrong, O. (1965). Clin. Sci., 28, 325.

Rieselbach, R. E., Bentzel, C. J., Cotlove, E., Frei, E., III, and Freireich, E. J. (1964). Amer. F. Med., 37, 872 .

Rundles, R. W., Wyngaarden, J. B., Hitchings, G. H., Elion, G. B., and Silberman, H. R. (1963). Trans. Ass. Amer. Phycns, 76, 126

Sandberg, A. A., Cartwright, G. E., and Wintrobe, M. M. (1956). Blood, 11, 154

Seegmiller, J. E., Laster, L., and Howell, R. R. (1963). New Engl. J. Med., 268, 712, 764, 821 .

Yü, T-F., and Gutman, A. B. (1964). Amer. F. Med., 37, 885.

\title{
Incidence of Candida in Hospital In-patients and the Effects of Antibiotic Therapy
}

\author{
B. J. SMITS,* M.B., B.S., M.R.c.P. ; A. P. PRIOR, $\dagger$ M.B., B.S., F.C.PATH. ; P. G. ARBLASTER, $\ddagger$ V.R.D., M.D., M.R.C.P.
}

Brit. med. 7., 1966, 1, 208-210

Until recently a majority of clinicians probably thought of candida only in relation to stomatitis in infants and vaginitis in women. Few appreciated its widespread distribution or its potential pathogenicity, particularly in debilitated or diabetic patients or after antibiotic or steroid therapy. Thus it may well go unrecognized as an infecting agent.

The widespread distribution of candida and its increase after broad-spectrum antibiotics has been studied at various sites. In addition carriers may be of importance because of their ability to infect others (Lepper et al., 1958-9). The place of the intestinal reservoir in relation to skin lesions has been discussed by Marten (1959), and the occurrence of Candida albicans in angular cheilitis by Cawson (1963), in intertrigo by Shelmire (1925), and in paronychia by Whittle et al. (1959).

In this study the incidence of oral and rectal candida and changes coincidental with antibiotic therapy in unselected patients admitted to hospital were investigated. Murdoch (1964) recommended a combination of the non-absorbed antifungal agent, nystatin, with tetracycline (Mysteclin), to overcome an increase of the intestinal reservoir of candida, and this hypothesis was also studied.

\section{Materials and Methods}

The study was undertaken in a small general hospital serving both urban and rural areas. All patients admitted to the medical

\footnotetext{
- Medical Registrar, South Warwickshire Hospital Group. Now at Nutrition and Intestinal Unit, Birmingham General Hospital + Consultant Pathologist, South Warwickshire Hospital Group. ‡ Consultant Chest Physician, South Warwickshire Hospital Group.
}

wards during one year were included in the study, except diabetics and those who had had steroid or antibiotic therapy in the previous year. Treatment was decided on clinical grounds, but where tetracycline was prescribed patients were given tetracycline or Mysteclin in a random fashion and under doubleblind conditions. Antibiotic dosage was judged according to the clinical requirements; tetracycline was generally given at $250 \mathrm{mg}$. q.i.d., and patients allocated to the antifungal combination received 250,000 units of nystatin with each $250 \mathrm{mg}$. of tetracycline. Penicillin was administered at a level of from 2 to 3 million units of benzylpenicillin intramuscularly daily.

Irrespective of antibiotic therapy, throat and rectal swabs were obtained on admission and again after five days. Standard throat swabs were used; rectal swabs were similar except for the addition of a short length of glass tubing, which protected the swab during its introduction through the anus, so as to prevent skin and anal margin contamination.

In the laboratory the swabs were inoculated on to Sabouraud's medium. Where bacterial contamination from the rectal swabs became evident reinoculation as described by J. Walker (personal communication, 1957) was performed to obtain pure cultures. Gram-stained films were examined for morphology and purity, and further techniques as described by Conant et al. (1954) were used to identify the organisms isolated. Chlamydospore production was assessed by the method of Dawson (1962), and further guidance on colonial forms and slide culture appearances was culled from Benham (1957).

An attempt was also made to assess any variations in symptoms by questioning patients on admission and again on the sixth and twelfth days for the presence and severity of 
abdominal discomfort, nausea, vomiting, pruritus ani, rashes, and alterations in bowel habits.

\section{Results}

A total of 199 patients were admitted to the trial, but 33 were later excluded because of inadequate documentation or group of nine had oral penicillin and are included only in the findings on admission, as the number was thought to be too small for further analysis.

Symptomatology.-Analysis of symptoms on admission and after 6 and 12 days made it clear that variations of these symptoms were largely due to the patient's primary condition and its progress. There was no difference in the incidence of symptoms assessed between the various treatment groups, nor was there any relation between symptoms and the presence of candida in mouth or rectal swabs.

Throat and Rectal Swabs on Admission.-Of the 166 patients assessed on admission, $46(28 \%)$ had throat swabs positive for candida and $14(8.4 \%)$ had positive rectal swabs. As the trial covered 12 months an analysis was made to show any seasonal variation in incidence, but no significant difference was found. A breakdown of age-groups, however, showed an increased incidence of candida in the mouths of patients on admission aged 41 years and over, with a consistent tendency to be more common in females than males. The effect of age and sex on the insidence of swabs on admission is shown in Fig. 1.

Throat and Rectal Swabs After 5 Days in Ward.-Of the 157 patients subsequently analysed, 85 were not given any death during the period of study. Of the remaining 166 a

form of antibiotic, 34 had tetracycline with or without nystatin, and 38 had intramuscular penicillin. The results of the swabs are shown in Fig. 2. The tetracycline and tetracycline/nystatin groups were not completely comparable, but as the latter group included more females and more patients over 41 years the differences tend to emphasize the effect of the added nystatin in overcoming the increase in candida.

Types of Candida Isolated.-Of the 57 positive throat swabs obtained on admission 22 were examined in greater detail for species identifications. The results were as follows: $C$. albicans, $73 \%$; C. kreusii, $14 \%$; C. tropicalis, $9 \%$; other species, $4 \%$.

\section{Discussion}

The proportion of patients with candida in the mouth on admission to hospital was $28 \%$, which is higher than the incidence of $10-17 \%$ found in healthy adults by Tanner et al. (1927), Todd (1937), and Basu et al. (1961), but lower than the $53 \%$ in hospital patients demonstrated by Stenderup and Pedersen (1962).

The frequency with which candida was found on rectal swabs was only $8.4 \%$, against the $27 \%$ shown in the faeces by Mackenzie (1961) in Edinburgh and by Winner (1960) in London. Possibly this is due to the avoidance of perianal contamination by the method of swabbing used in this investigation. Furthermore, the incidence of candida in both oral and rectal swabs increased with age.

Admission to a hospital had no effect on the incidence of candida, either in the mouth or in the gut, but the effect of antibiotics is clearly demonstrated. The proliferation of candida after broad-spectrum antibiotic therapy is a well-recognized phenomenon, as pointed out by Winner and Hurley (1964) in their review of the literature, but this study suggests that it can also occur with parenteral penicillin at the doses used and that the proliferation occurs after only five days' therapy. This supports similar observations by Childs (1956, 1957) and MacLean (1962) but is contrary to suggestions that proliferation of candida occurs only after prolonged antibiotic therapy (Drouhet, 1957 ; Murdoch, 1964).

The effect of nystatin in abolishing the overgrowth of candida in the intestines is demonstrated in the present study, despite the small numbers involved, and agrees with similar trials by other workers (Childs, 1956, 1957 ; Larkin, 1959 ; Metzger et al., 1956-7 ; Newcomer et al., 1954-5).

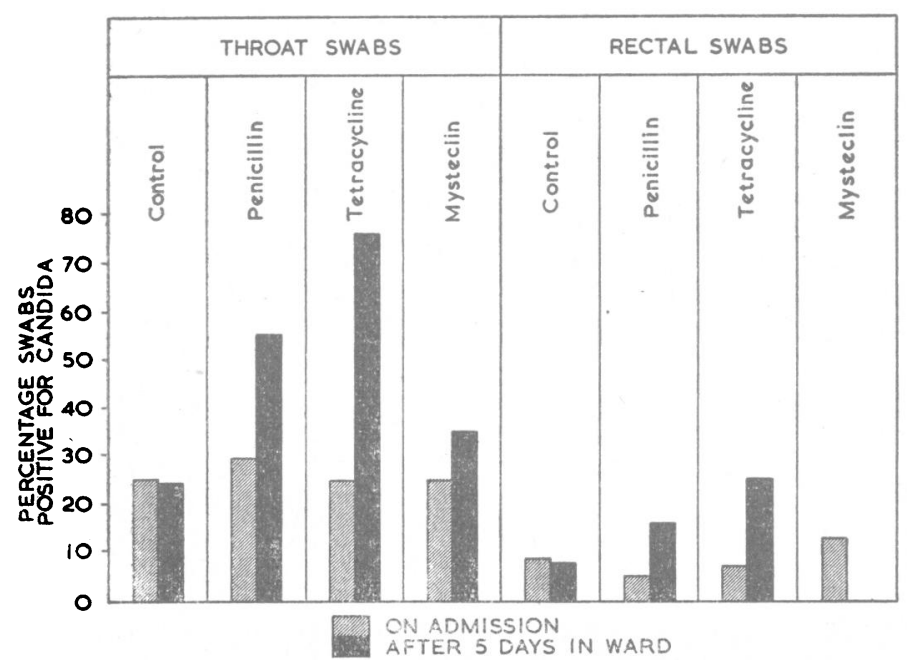

FIG. 2.-Incidence of swabs positive for candida before and after five days in hospital, according to treatment groups.
It is more difficult to understand the diminution of oral proliferation of candida in patients receiving the tetracycline/ nystatin combination, as nystatin is not absorbed when given by mouth (Newcomer et al., 1954-5) and can have no local effect.

Despite the consistent findings by various authors of a greater tendency for candida to be found in patients on broad-spectrum antibiotics, there has been incomplete correlation between proliferation of candida and side-effects. Larkin (1959) and Childs (1956) showed close correlation between faecal candida and gastro-intestinal symptoms. Robinson (1957-8), Chamberlain et al. (1958), and Stone and Mersheimer (1955-6) found a reduction in side-effects when an antifungal agent such as nystatin was given with broad-spectrum antibiotics. On the other hand, in a large series of cases, Robinson (1954) found a negligible incidence of symptoms proved to be due to candida in patients being treated with antibiotics, and Younger et al. (1959) failed to show a cause-and-effect relationship between the proliferation of candida and gastro-intestinal symptoms in patients treated with broad-spectrum antibiotics. This trial was also unable 
to show a correlation between overgrowth of candida and adverse symptoms after short-term antibiotic therapy.

Proliferation of candida in many patients did not cause significant morbidity in this trial, but in view of the morbidity and even mortality which candida can occasionally produce (Reynell et al., 1953 ; Caplan, 1955), it would seem wise to contain or reduce the reservoir of candida when using antibiotics in certain patients.

\section{Summary}

Of 166 patients admitted to a general medical ward in a year $28 \%$ were shown to have positive throat swabs and $8.4 \%$ to have positive rectal swabs for candida, the incidence increasing with age and being more common in women though not increasing after five days in hospital.

The administration of parenteral penicillin or oral tetracycline markedly increased the incidence of positive throat and rectal swabs after five days, but where the latter antibiotic was combined with nystatin this tendency was suppressed.

In the present study gastro-intestinal symptoms were not affected by short courses of antibiotics, as assessed after 6 and 12 days, but because of the potential pathogenicity of candida it is felt wise, in selected patients, to administer nystatin by mouth in combination with antibiotic therapy.

Our thanks are due to Dr. K. Cross for statistical advice, to Messrs. Squibb \& Co. for kindly providing the tetracycline and the Mysteclin, and to Dr. Brian Cromie for his encouragement and help in assessing the results. We have also to thank Dr. W. M. Priest and Dr. S. R. F. Whittaker for permission to include patients under their care in this trial.

\section{REFERENCES}

Basu, R., Basu, N., and Banerjee, A. K. (1961). Bull. Calcutta Sch. trop. Med., 9, 20.

Benham, R. W. (1957). F. chron. Dis., 5, 460.

Caplan, H. (1955). Lancet, 2, 957.

Cawson, R. A. (1963). Brit. dent. F., 115, 441.

Chamberlain, C., Burros, H. M., and Borromeo, V. (1958). Antibiot. Med., 5, 521 .

Childs, A. J. (1956). Brit. med. 7., 1, 660.

(1957). Scot. med. $\dot{f}_{.,}, 2,400$.

Conant, N. F., Smith, D. T., Baker, R. D., Callaway, J. L., and Martin, D. S. (1954). Manual of Clinical Mycology, 2 nd ed. Saunders, Philadelphia and London.

Dawson, C. O. (1962). Sabouraudia, 1, 214.

Drouhet, E. (1957). Sem. Hôp. Paris, 33, 843.

Droukin, R. (1959). Lancet, 1, i228.

Lepper, M. H., Lockwood, J., Spies, H. W., and Rubenis, M. (1958-9). Antibiot. Ann., p. 666.

Mackenzic, D. W. R. (1961). Sabouraudia, 1, 8.

MacLean, K. (1962). Medical Treatment, 2nd ed., p. 715. Churchill, London.

Marten, R. H. (1959). Brit. F. Derm., 71, 422.

Metzger, W. J., Skigmann, F., Jenkins, C. J., Pamuken, S. F., and Kaminski, $\ddot{L}$. (1956-7). Antibiot. Ann., p. 208.

Murdoch, J. McC. (1964). Textbook of Medical Treatment, edited by D. Dunlop, S. Davidson, and S. Alstead, 9th ed., p. 71. Livingstone, Edinburgh and London.

Newcomer, J. D., Wright, E. T., and Steinberg, T. H. (1954-5). Antibiot. Ann., p. 686 .

Reynell, P. C., Martin, E. A., and Beard, A. W. (1953). Brit. med. 7.,

1, 919. H. M. (1954). Arch. Derm. Syph. (Chic.), 70, 640.

Robinson, M. (1957-8). Antibiot. Ann., P. 451.

Shelmire, B. (1925). Arch. Derm. Syph. (Chic.), 12, 789.

Stenderup, A., and Pedersen, G. T. (1962). Acta path. microbiol. scand., $54,462$.

Stone, M. L., and Mersheimer, W. L. (1955-6). Antibiot. Ann., p. 862. Abt Orig 103, 94

Todd, R. L. (1937). Amer. f. Hyg., 25, 212

Whittle, C. H., Moffatt, J. L., and Davis, R. A. (1959). Brit. F. Derm.,

71, 1.
Winner, H. I. (1960). Unpublished data quoted by Winner and Hurley (1964), p. 125. R. (1964). Candida Albicans, p. 62. Churchill, London.

Younger, D., Epifano, L. D., Dipillo, F., Hoffman, I., Thaler, E., and Yarvis, M. (1959). Antibiot. Med., 6, 216.

\title{
Treatment of Trigeminal Neuralgia with Carbamazepine : a Follow-up Study
}

\author{
J. G. GRAHAM,* M.B., M.R.C.P., M.R.C.P.ED. ; K. J. ZILKHA, † M.D., M.R.C.P.
}

Brit. med. F., 1966, 1, 210-211

There have been several reports of the use of carbamazepine (Tegretol ; 5-carbamyl-dibenz(b.f.)-azepine) in the management of trigeminal neuralgia (Blom, 1962, 1963 ; Spillane, 1963, 1964 ; McArdle, 1963 ; Taylor, 1963 ; Campbell, Graham, and Zilkha, 1966). These reports, pointing to a $60-80 \%$ success rate, have been mainly concerned with treatment in the short term.

In order to assess the value of the drug in the long term the present study was undertaken.

\section{Material and Methods}

The case records of 96 patients with trigeminal neuralgia treated with carbamazepine at the National Hospital, Queen Square, have been assessed with reference to the success or failure of this method of treatment over a prolonged period.

The cases have been arbitrarily divided into three groups according to the length of follow-up. The follow-up period was defined as the interval between starting carbamazepine and the last consultation. All patients were complaining of pain

* Academic Registrar, National Hospital, Queen Square, London. + Physician, National Hospital, Queen Square, London. typical of trigeminal neuralgia when they were first put on the drug.

Group A.-Forty-four patients, followed up for 1 to 11 months, with a mean of 5.3 months.

Group B.-Forty-two patients, followed up for 12 to 23 months, with a mean of 14.8 months.

Group C.-Ten patients, followed up for 24 to 30 months, with a mean of 26.6 months.

The results in each group were analysed separately, and four categories were recorded: (1) pain-free ; (2) some slight pain but well controlled and content ; 3 ) poorly controlled though perhaps slightly improved; (4) failed. The results are summarized in the Table.

Dosage of Carbamazepine.-All patients were started on a dose of $100 \mathrm{mg}$. four times daily. Those who did not show a good response within 48 hours had their dosage doubled to $200 \mathrm{mg}$. four times daily. Of the 71 patients remaining after exclusion of the failures, 59 were still taking the drug when last seen. Twenty of these were doing so intermittently and at irregular intervals, a small dose usually being sufficient to keep the occasional spasm at bay. The other 39 were evenly distributed, half taking an average dose of $400 \mathrm{mg}$. daily and the other half $800 \mathrm{mg}$. daily. 